Functional

Ecology 2001

15, 85-95

\title{
Effects of growing conditions and source habitat on plant traits and functional group definition
}

\author{
A. R. DYER,${ }^{* \dagger}$ D. E. GOLDBERG, ${ }^{*}$ R. TURKINGTON $\$$ and C. SAYRE $\$$ \\ *Department of Biology, University of Michigan, Ann Arbor, MI 48109, USA, and \$Department of Botany, \\ University of British Columbia, Vancouver, Canada
}

\begin{abstract}
Summary
1. Plant functional groups are used to describe patterns of community organization. However, they are defined either by suites of correlated traits or by species groupings, and the responses of these two definitions to changing environmental conditions are unknown.
\end{abstract}

2. We assessed 14 growth and morphological traits under low- and high-resource conditions of 42 annual plant species from two source communities in Israel that differed in resource availability. As current theory predicts, plants growing in the high-resource treatment were larger, had twofold greater relative growth rate (RGR) and thinner leaves, and allocated less biomass to roots than plants grown in the low-resource treatment. Differences in these traits were less consistent between the two source communities. Instead, taxonomic groups (grasses, legumes and a group of other forbs), regardless of source, differed in most characteristics.

3. Three general groups of species (functional groups) were identified in both resource treatments using cluster analysis on all 14 traits. In both resource treatments monocots were almost completely separated into one distinct cluster, regardless of source habitat, while the two other, mainly dicot, clusters were partially separated by habitat. However, the species composition and trait characterization of the dicot clusters differed strongly between treatments. Under low-resource conditions the two dicot clusters were separated by size traits and seed mass, but under high-resource conditions, they were separated by above-ground size, morphology and RGR.

4. Principal components analysis demonstrated inconsistency in relationships among traits and species groupings between treatments. The first two principal components emphasized different aspects of growth depending on the treatment; the third axis was defined by growth rates. As with the cluster analysis, plots of species scores revealed relatively little separation of species by habitat.

5. The response of each species varies for different traits and with growing conditions. Variation may differ among species within a functional group, producing different definitions of functional groups under different experimental conditions. Because most functional group analyses are performed on data collected without manipulation of growing conditions, conclusions concerning the response of species or communities to changes in environmental conditions may be problematic.

Key-words: annual species, cluster analysis, environmental change, principal components analysis, resource availability, trait correlations

Functional Ecology (2001) 15, 85-95

\section{Introduction}

Many ecologists agree that complex community structure can be simplified by categorizing species

$\dagger$ To whom correspondence should be addressed. Present address: Department of Biology and Geology, University of South Carolina-Aiken, Aiken, SC 29801-6309, USA. into plant functional groups (PFGs) based on suites of correlated traits (Lavorel et al. 1997; Smith, Shugart \& Woodward 1997). The concepts of 'character syndrome' (Stebbins 1974); 'adaptive strategies' (Grime 1977); 'stress response syndrome' (Chapin 1991); and 'plant ecology strategy scheme' (Westoby 1998) all suggest that suites of morphological and physiological characteristics in plants are correlated with adaptive 
86

A. R. Dyer et al.

(C) 2001 British

Ecological Society, Functional Ecology, $\mathbf{1 5}, 85-95$ response to environmental conditions. For example, plants from more productive habitats often have faster growth rates and larger structures, are taller relative to weight, and have thinner leaves and roots (Chapin 1980, 1991; Grime 1977; Grime et al. 1997; Lambers \& Poorter 1992; Schlichting 1986; Tilman 1988). Ultimately, one important goal of PFG analysis is to use this information on correlated traits to predict the response of vegetation to environmental change, in lieu of detailed information on each species.

However, there are three major types of limitations to the usefulness of PFGs for predicting response to environmental change. First, as Lavorel et al. (1997) point out, most PFG analyses have included species from a range of different growth forms, but tend to recover the easily recognized phenotypic characteristics such as growth form (e.g. Diaz \& Cabido 1997; McIntyre, Lavorel \& Tremont 1995). We also need to establish whether trait associations are found within growth forms and, if so, whether these are similar to those found across growth forms (Lavorel et al. 1997).

Second, PFGs must exhibit repeatability (Gitay $\&$ Noble 1997). Data collected on the same set of species growing under different conditions must define the same (or similar) PFGs. This implies either a similar pattern of correlation among traits across environments, or that particular groups of species respond to environmental variation with similar changes in phenotypic expression. Neither is necessarily predicted by current theory (Schlichting 1986). The third limitation is what Gitay \& Noble (1997) refer to as 'uniqueness': that different analytical techniques applied to the same data should arrive at similar conclusions.

Consequently, PFG definitions may vary with changes in trait means, correlations among traits, differential species responses, and so on. Assessing these conditions for all the species comprising a community is expensive and laborious, and techniques for describing PFGs have been developed specifically as rapid and inexpensive alternatives for describing vegetation. Nevertheless, their reliability must be established experimentally.

Here we describe data generated using a standard methodology for assessing plant traits (Hendry \& Grime 1993), then compare the effects of different growing conditions (resource availability) on changes in trait means and on the definition and composition of resultant PFGs. Our species pool comprised a single life form, annual plants, representing many vascular plant families with a wide range of traits within the annual life form. We used species from two habitats, a coastal Mediterranean community and a considerably drier desert community, to test predictions about traits associated with plants from environments with different productivity.

We first ask how growth and morphological traits respond to resource availability in terms of resources available during growth and in terms of resource availability of the habitat. We test the predictions that plants from more productive habitats, or growing under more productive conditions, have smaller allocation to below-ground structures, thinner leaves and roots, are taller relative to their weight, and have faster growth rates and larger size (Berendse \& Elberse 1990; Chapin 1980, 1991; Grime 1977; Grime \& Hunt 1975, 1979; Poorter \& Remkes 1990; Tilman 1990). Second, we ask if patterns of trait responses among annuals define groups of functionally similar species, and whether these groups are independent of habitat, taxonomic affiliation, or both. Third, we ask whether groups of functionally similar species have consistent composition or patterns of trait responses in nutrient-poor and nutrient-rich conditions. We discuss the implications of these results for the use of PFG analysis in predicting vegetation shifts due to environmental change.

\section{Methods}

\section{HABITAT DESCRIPTION}

We collected seed from 42 taxa of annuals representing a range of families (Table 1) from two semistabilized sand dune communities in Israel, located about $240 \mathrm{~km}$ apart; one species (Cutandia dichotoma) was represented in both communities. The first site is coastal (near Caesarea; 32 $30^{\prime} \mathrm{N}, 34^{\circ} 55^{\prime} \mathrm{E}$ ) in the Ceratonio-Pistacietum lentisci typicum plant association, with an average annual precipitation of $550 \mathrm{~mm}$ (description of vegetation after Zohary 1982). The second site is in the central Negev desert (Holot Mashabim Nature Reserve; $31^{\circ} 00^{\prime} \mathrm{N}$; 34 ${ }^{\circ} 44^{\prime} \mathrm{E}$ ) in the Stipagrostio-Artemisietum monospermae plant association, which receives an average annual precipitation of $110 \mathrm{~mm}$. Precipitation for both communities is highly seasonal, with a potential growing season from November to May. The fivefold difference in annual precipitation between the two sites corresponds to a fivefold difference in total productivity, measured by biomass production of annuals, and to a 2.5-fold difference in density of annuals (unpublished data). The sites also differ in species composition, although they overlap considerably in the genera present and a few species are common to both habitats. Although it is argued that desert annuals occupy productive, if temporary, habitats (e.g. Grime 1979), we expect that our desert annual community is probably more water- and nitrogen-limited than the coastal annual community. While the annuals in both habitats grow only during the winter rainy season, the intervals between rainfall events tend to be much longer in the desert, increasing the probability of drought even during the growing season. In addition, although both habitats occur on sandy soils and ammonium concentrations are similar between habitats, nitrate concentrations in the coastal habitat are an order of magnitude greater than in the desert (unpublished data). 
87

Effects on plant traits and

functional groups

Table 1. Species used for trait analysis by source (desert or coastal), taxonomic group (grass, forb, or legume), and family. Two-letter abbreviations are used for species identity in Fig. 2

\begin{tabular}{|c|c|c|c|}
\hline Desert species & Abbrev. & Group & Family \\
\hline Filago desertorum Pomel. & $\mathrm{Fd}$ & Forb & Asteraceae \\
\hline Picris asplenoides L. & $\mathrm{Pp}$ & $\mathrm{F}$ & Asteraceae \\
\hline Diplotaxis harra (Forssk.) Boise & $\mathrm{Dh}$ & $\mathrm{F}$ & Brassicaceae \\
\hline Erucaria pinnata (Viv.) Taekh. et Boulos & Ep & $\mathrm{F}$ & Brassicaceae \\
\hline Mathiola livida (Delile) DC. & $\mathrm{Mv}$ & $\mathrm{F}$ & Brassicaceae \\
\hline Reboudia pinnata (Viv.) O.E. Schulz & $\mathrm{Rn}$ & $\mathrm{F}$ & Brassicaceae \\
\hline *Silene sp. & Ss & $\mathrm{F}$ & Caryophyllaceae \\
\hline *Plantago cylindrica Forssk. & $\mathrm{Pc}$ & $\mathrm{F}$ & Plantaginaceae \\
\hline *Plantago ovata Forssk. & Po & $\mathrm{F}$ & Plantaginaceae \\
\hline * Rumex pictus Forssk. & $\mathrm{Rp}$ & $\mathrm{F}$ & Polygonaceae \\
\hline Crucianella membranacea Boiss. & $\mathrm{Cm}$ & $\mathrm{F}$ & Rubiaceae \\
\hline Hippocrepis multisiliquosa $\mathrm{L}$. & $\mathrm{Hm}$ & Legume & Fabaceae \\
\hline *Trifolium tomentosum L. & $\mathrm{Tt}$ & $\mathrm{L}$ & Fabaceae \\
\hline *Trigonella arabica Delile & $\mathrm{Ta}$ & $\mathrm{L}$ & Fabaceae \\
\hline Ammochloa palaestina Boiss. & Ap & Grass & Poaceae \\
\hline *Bromus fasciculatus C. Presl & $\mathrm{Bf}$ & G & Poaceae \\
\hline Ctenopsis pectinella (Delile) De Not. & $\mathrm{Ct}$ & $\mathrm{G}$ & Poaceae \\
\hline * Cutandia dichotoma (Forssk.) Trabut & $\mathrm{Cd}$ & $\mathrm{G}$ & Poaceae \\
\hline Vulpia brevis Boiss. et Kotschy & $\mathrm{Vb}$ & $\mathrm{G}$ & Poaceae \\
\hline Vulpia myuros (L.) C.C. Gmelin & $\mathrm{Vm}$ & $\mathrm{G}$ & Poaceae \\
\hline \multicolumn{4}{|l|}{ Coastal species } \\
\hline Chrysanthemum viscosum Desf. & $\mathrm{Cv}$ & Forb & Asteraceae \\
\hline Senecio joppensis Dinsmore & $\mathrm{Sj}$ & $\mathrm{F}$ & Asteraceae \\
\hline Senecio vernalis Waldst. et Kit & Sv & $\mathrm{F}$ & Asteraceae \\
\hline Brassica tournefortii Gouan & $\mathrm{Bt}$ & $\mathrm{F}$ & Brassicaceae \\
\hline Paronychia argentea Lam. & $\mathrm{Pa}$ & $\mathrm{F}$ & Caryophyllaceae \\
\hline * Silene colorata Poiret & Sc & $\mathrm{F}$ & Caryoplyllaceae \\
\hline Erodium laciniatum (Cav.) Willd. & $\mathrm{El}$ & $\mathrm{F}$ & Geranaceae \\
\hline *Plantago sarcophylla Zohary & $\operatorname{Pr}$ & $\mathrm{F}$ & Plantaginaceae \\
\hline *Rumex bucephalophorus L. & $\mathrm{Rb}$ & $\mathrm{F}$ & Polygonaceae \\
\hline *Rumex occultans Sam. & Ro & $\mathrm{F}$ & Polygonaceae \\
\hline Lotus halophilus Boiss. et Spruner & Lh & Legume & Fabaceae \\
\hline Medicago littoralis Loisel. & M1 & $\mathrm{L}$ & Fabaceae \\
\hline *Trifolium palaestinum Boiss. & $\mathrm{Tp}$ & $\mathrm{L}$ & Fabaceae \\
\hline *Trigonella cylindracea Desv. & $\mathrm{Tc}$ & $\mathrm{L}$ & Fabaceae \\
\hline *Trigonella stellata Forssk. & Ts & $\mathrm{L}$ & Fabaceae \\
\hline Brachypodium distachyon (L.) Beauvois & $\mathrm{Bd}$ & Grass & Poaceae \\
\hline *Bromus rigidus Roth & $\mathrm{Br}$ & G & Poaceae \\
\hline *Cutandia dichotoma (Forssk.) Trabut & $\mathrm{Cc}$ & $\mathrm{G}$ & Poaceae \\
\hline *Cutandia memphytica (Sprengel) K. Richter & $\mathrm{Cu}$ & $\mathrm{G}$ & Poaceae \\
\hline *Cutandia philistaea (Boiss.) Jackson & $\mathrm{Cp}$ & $\mathrm{G}$ & Poaceae \\
\hline Lagurus ovatus L. & Lo & $\mathrm{G}$ & Poaceae \\
\hline Phleum subulatum (Savi) Ascherson et Graebner & Ps & $\mathrm{G}$ & Poaceae \\
\hline
\end{tabular}

*The 19 species used for phylogenetic independent contrasts (PIC). Nomenclature follows Feinbrun-Dothan \& Danin (1991).

\section{EXPERIMENTAL DESIGN AND GROWTH MEASUREMENTS}

We used standardized procedures for data collection under controlled conditions (Hendry \& Grime 1993) to reveal inherent growth properties of the species of interest (Grime \& Hunt 1975). Plants were grown at the University of British Columbia in a Conviron environmental chamber with a 13/11 h (light/dark) photoperiod, a $25 / 10{ }^{\circ} \mathrm{C}$ light/dark temperature cycle, and $10 \%$ relative humidity to simulate natural conditions. Light was supplied by 16 full-spectrum fluorescent bulbs (Vitalite, UHO). Each of eight blocks had four individuals of each of the 42 taxa, randomly assigned to a harvest, 7 or 21 days after emergence, and high- or low-resource (nutrient and water) treatments. Because of space limitations, blocks were planted sequentially in pairs on 1 March, 27 March, 26 April and 26 May 1994.

Two to 10 seeds of each species were sown into forest seedling tubes $4 \mathrm{~cm}$ diameter by $20 \mathrm{~cm}$ deep, filled with sterile sand. In the high-resource treatment, slow-release fertilizer pellets (NPK $14: 14: 14$ ) were mixed into the sand before planting at a rate of $130 \mathrm{ml}$ fertilizer per 161 sand. Plants were watered daily with $20 \mathrm{ml} 0 \cdot 4 \%$ (v/v) solution of dissolved fertilizer (NPK $20: 20: 20$ ). Plants in the low-resource treatment received $20 \mathrm{ml}$ water every second day with
Ecological Society, Functional Ecology, 15, 85-95 
88

A. R. Dyer et al.
Table 2. Fourteen plant traits used in univariate analyses, cluster analyses and principal components analyses (PCA). Rate traits (RGR and ULR) were calculated across the 14 day time period between harvests. All other performance and morphological traits were calculated from the final harvests at 21 days postemergence

no nutrient supplementation. As in the source environments, the high-resource treatment supplied more nutrients and water than the low-resource treatment.

For each species, the first seedling to emerge from either of the two tubes in each resource treatment in a block was designated for the day 7 harvest; the first seedling to emerge in the second tube became the day 21 harvest. All subsequent seedlings emerging in the same tubes were removed.

At each harvest we measured the number of leaves, total leaf area, and height of each plant. Roots and shoots were separated, dried and weighed. Roots were further separated into the top $20 \mathrm{~mm}$ of the main root and the rest of the root system. From these traits we calculated both root and shoot relative growth rate (RGR) and five morphological traits ( Table 2). Note that data are for leaf area ratio (LAR, leaf area to total shoot mass) rather than specific leaf area (leaf area to leaf mass) for better comparisons between dicots and grasses. This was done because leaf and stem areas were measured separately for dicots, but not for grasses.

We consider measurements of performance to be size-related traits that are likely to have a strong positive correlation with fitness in any environment. Morphological traits measure changes in allocation, and have an unknown correlation with fitness that could vary with environment. Additionally, we used the number of days to seedling emergence and one trait (seed mass) that was constant across treatments ( Table 2).

(C) 2001 British

Ecological Society, Functional Ecology, 15, 85-95

\section{DATA ANALYSIS}

We report only the data collected from the day 21 harvest, with the exception of rate traits that were calculated over the time interval. Ideally, the mean trait values for each species would be calculated as the mean over all blocks, so that we would also have an estimate of variation in traits for each species. However, this was not possible for the rate traits (RGR and unit leaf rate, ULR) because of missing values within blocks. Therefore we first calculated the mean for each performance variable over all blocks at a given harvest and resource treatment for each species, then used species means to calculate the three rate traits defined in Table 2 . The trait means for each species were used in all subsequent analyses, thus we could not include block as an explicit factor in any of the analyses, nor could we evaluate within-species variation in response to treatment.

To answer our first question and test predictions about the effect of resource availability and habitat on growth and morphological traits, we first conducted analysis of variance on each trait. Because the data set included species from several families, the ANOVAs included taxonomic group as a factor: grasses (13 species), legumes (eight species), and all other dicotyledonous species (forbs: 21 species with too few in any family to be treated as a separate category). These three-way ANOvas used species as replicates for each of the combinations of treatment, habitat and taxonomic group. Trait data are available on request.

To account for lack of taxonomic independence due to the seven genera (19 species) common to the habitats (Table 1), we conducted phylogenetic independent contrasts (PICs) (Silvertown \& Dodd 1996) for each trait and compared the results from paired $t$ tests $(P<0.05)$ to the trait ANOvAs. The results did not differ when tests included all possible congeneric pairs $(n=12)$ or just one randomly chosen pair from each genus $(n=7)$; therefore we report only the 
89

Effects on plant traits and

functional groups former. Agreement between ANOVAs and PICs would indicate that the direction of response among the congeneric pairs was consistent with the rest of the species in the sample.

To answer our second and third questions concerning the identification and consistency of PFGs, we used a hierarchical clustering algorithm (Ward's method, JMP $3 \cdot 2$, SAS Institute Inc, Cary, NC, USA) to generate dendrograms with all 42 taxa based on seed mass, time to emergence, and the 12 growth and morphological traits. One dendrogram was produced for each of the two resource treatments. Dendrograms allowed us to identify clusters as PFGs, and to compare the species composition and trait means of these groups between treatments and habitats.

To determine which traits were important in defining the PFGs, we compared the means of each of the 14 traits among the groups defined in each resource treatment using one-way ANOVA and protected multiple comparisons (Tukey's HSD). This determined which traits contributed to the definition of the PFGs within treatments. We then compared which traits were most important in defining the PFGs between the treatments.

The most direct way to compare the relationships among traits between treatments would be to test their equality of covariance matrices (B. Shipley, personal communication). However, we could not use this test because of inadequate replication within species $(n \leq 8)$ for accurate estimates of variance. Instead, we used the less direct approach of comparing trait loadings from principal components analysis (PCA) to determine which subsets of traits were positively and negatively correlated within a treatment. We also compared the rotated species scores for the first three principal components among the clusters for each treatment with one-way ANOvA, as a second approach to characterizing the PFGs defined by the clustering algorithm. Finally, we used the trait loadings from the PCA and the trait means from the cluster analysis to compare the similarity between the two techniques for defining PFGs.

\section{Results}

\section{TRAIT MEANS AND SPECIES RESPONSES}

Three-way ANOVA indicated highly significant differences between the resource treatments for all growth and morphological traits (Table 3). Increased nutrient and water availability led to a predictably greater than twofold increase in shoot RGR and corresponding increases in all measures of plant size for species from both habitats (Fig. 1c-f). Plastic responses of morphological traits were more mixed with respect to the predictions. As predicted, allocation to roots decreased, ULR and LAR increased, and upper root sections became more robust as resource availability increased (Fig. 1j,k,m,n). Contrary to our predictions, plants were shorter relative to their mass in nutrient-rich conditions (Fig. 11).

Comparisons of taxa from the less-fertile and morefertile habitats showed generally similar patterns, although differences were generally weaker than were plastic responses to the resource treatments (Table 3, Fig. 1). While coastal plants were, on average, significantly larger than the desert plants for most size measures, leaf numbers were similar and, ignoring taxonomic group, shoot and root RGR were almost identical between the habitats (Table 3, Fig. 1g,h). Instead, the differences in mean plant size between habitats were probably due to the significantly larger initial size of coastal plants $(\approx 2 \cdot 5$-fold difference in seed mass). While root length to mass ratio (RLM) and height to shoot mass ratio (HSM) showed similar patterns whether habitat or growing conditions

Table 3. Results of three-way ANOvAs on trait means from 42 taxa of coastal and desert annuals grown in low- and highresource treatments. Analyses of growth variables (leaf number to RGR) were done without a biomass outlier (Bromus rigidus) that was non-responsive to resource level and strongly influenced effects involving taxonomic group and source (Figs 2 and 3). See Fig. 1 for trait means

\begin{tabular}{|c|c|c|c|c|c|c|c|c|}
\hline Trait & $r^{2}$ & $\begin{array}{l}\text { Resource } \\
\text { level (R) }\end{array}$ & $\begin{array}{l}\text { Source } \\
\text { habitat (S) }\end{array}$ & $\mathrm{R} \times \mathrm{S}$ & $\begin{array}{l}\text { Taxonomic } \\
\text { group }(\mathrm{T})\end{array}$ & $\mathrm{R} \times \mathrm{T}$ & $\mathrm{S} \times \mathrm{T}$ & $\mathrm{R} \times \mathrm{S} \times \mathrm{T}$ \\
\hline Seed mass & $0 \cdot 11$ & - & $0 \cdot 0014$ & - & ns & - & ns & - \\
\hline Time to emergence & $0 \cdot 31$ & ns & ns & ns & $<0 \cdot 0001$ & ns & ns & ns \\
\hline Leaf number & 0.63 & $<0 \cdot 0001$ & ns & ns & $<0 \cdot 0001$ & $0 \cdot 0182$ & ns & ns \\
\hline Leaf area & $0 \cdot 39$ & $<0 \cdot 0001$ & $0 \cdot 0096$ & $0 \cdot 0362$ & $0 \cdot 0040$ & $0 \cdot 0063$ & ns & ns \\
\hline Plant height & 0.73 & $<0.0001$ & $0 \cdot 0027$ & ns & $<0.0001$ & $<0.0001$ & ns & ns \\
\hline Root mass & $0 \cdot 14$ & $0 \cdot 0169$ & $<0 \cdot 0001$ & ns & ns & ns & ns & ns \\
\hline Shoot mass & $0 \cdot 36$ & $<0.0001$ & $0 \cdot 0018$ & $0 \cdot 0485$ & $0 \cdot 0128$ & $0 \cdot 0170$ & ns & ns \\
\hline RGRr & $0 \cdot 40$ & $<0 \cdot 0001$ & ns & ns & $0 \cdot 0029$ & $0 \cdot 0227$ & ns & ns \\
\hline RGRs & $0 \cdot 79$ & $<0 \cdot 0001$ & ns & ns & $0 \cdot 0012$ & $0 \cdot 0004$ & $0 \cdot 0257$ & ns \\
\hline LAR & $0 \cdot 68$ & $<0.0001$ & ns & ns & $<0 \cdot 0001$ & ns & ns & ns \\
\hline RLM & $0 \cdot 32$ & $0 \cdot 0160$ & 0.0006 & ns & ns & $0 \cdot 0149$ & ns & ns \\
\hline HSM & 0.71 & $<0.0001$ & 0.0007 & ns & $<0.0001$ & $<0.0001$ & $0 \cdot 0119$ & ns \\
\hline RWR & $0 \cdot 83$ & $<0.0001$ & ns & ns & $<0.0001$ & $<0.0001$ & ns & ns \\
\hline ULR & $0 \cdot 27$ & $0 \cdot 0203$ & ns & ns & $<0.0001$ & $\mathrm{~ns}$ & ns & ns \\
\hline
\end{tabular}

2001 British Ecological Society, Functional Ecology, 15, 85-95 


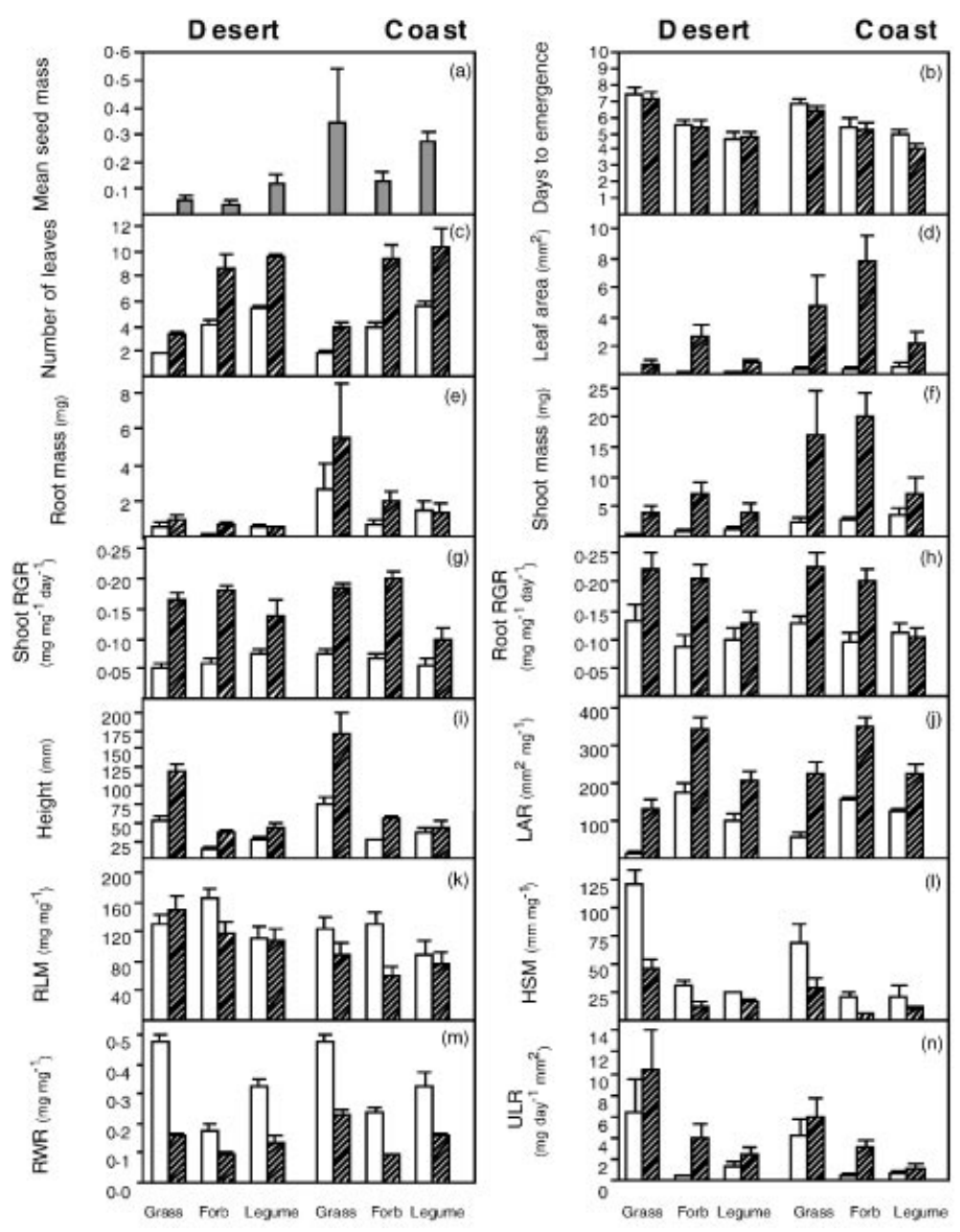

Fig. 1. Two-way interaction plot for mean seed mass $( \pm \mathrm{SE})$ and three-way interaction plots of the mean response of 13 traits $( \pm \mathrm{SE})$ in low- and high-resource treatments (ANOVA results in Table 2). Pairs of open and shaded columns represent low- and high-resource treatments, respectively, for each of the three taxonomic groups, with desert means on the left and coastal means on the right in each panel.

Table 4. Trait means of congeneric pairs of species shared by both source habitats in low- and high-resource treatments. Significantly different means were determined using phylogenetic independent contrasts (PIC) on 12 congener pairs. Comparisons with Bromus rigidus were excluded in the first eight traits listed

\begin{tabular}{|c|c|c|c|c|c|c|}
\hline & \multicolumn{3}{|c|}{ Low-resource treatment } & \multicolumn{3}{|c|}{ High-resource treatment } \\
\hline & Desert & & Coast & Desert & & Coast \\
\hline Time to emergence & $5 \cdot 4$ & & $5 \cdot 2$ & $6 \cdot 3$ & $* *$ & $5 \cdot 1$ \\
\hline Leaf number & $3 \cdot 3$ & $*$ & $3 \cdot 7$ & $7 \cdot 2$ & & $8 \cdot 1$ \\
\hline Leaf area & $0 \cdot 136$ & $*$ & $0 \cdot 367$ & $1 \cdot 91$ & $*$ & $3 \cdot 21$ \\
\hline Plant height & $35 \cdot 3$ & & $43 \cdot 1$ & $76 \cdot 3$ & & $82 \cdot 0$ \\
\hline Root mass & $0 \cdot 473$ & $*$ & 0.959 & 0.834 & $*$ & $1 \cdot 39$ \\
\hline Shoot mass & 0.903 & * & $2 \cdot 436$ & $6 \cdot 93$ & $*$ & $1 \cdot 13$ \\
\hline RGRr & $0 \cdot 084$ & & $0 \cdot 098$ & $0 \cdot 178$ & & $0 \cdot 172$ \\
\hline RGRs & $0 \cdot 090$ & & $0 \cdot 084$ & $0 \cdot 165$ & & $0 \cdot 165$ \\
\hline LAR & $93 \cdot 4$ & $*$ & 101 & 263 & & 231 \\
\hline RLM & 142 & $*$ & 112 & 103 & $*$ & $81 \cdot 2$ \\
\hline HSM & $51 \cdot 7$ & & $40 \cdot 0$ & $16 \cdot 4$ & & $16 \cdot 7$ \\
\hline RWR & $0 \cdot 338$ & & $0 \cdot 342$ & $0 \cdot 118$ & & $0 \cdot 144$ \\
\hline ULR & $0 \cdot 008$ & & $0 \cdot 004$ & $0 \cdot 018$ & & 0.008 \\
\hline
\end{tabular}

$*, P \leq 0 \cdot 05 ; * *, P \leq 0 \cdot 01$. were compared, species of the two habitats did not differ in LAR, root weight ratio (RWR), or ULR. Finally, the magnitude of response of most traits to an increase in resources was similar for the two habitats: there were few significant interactions between resource treatment and habitat (Table 3 ).

The responses of congeneric species shared by each habitat were partially consistent with the ANOVA results (Table 4). With two exceptions, all traits that showed significant source differences in the ANOVA (Table 3) also showed significant source differences in the PICs in one or both of the resource treatments. Directions and magnitudes of effects were also similar whether generic membership was included (Table 4) or not included (Fig. 1) in the analysis. The two exceptions (plant height and HSM) appeared to be due to the two grass genera tested. Among the dicot generic pairs, results from the PICs were similar to the overall comparisons: height was greater for the coastal species (paired $t$-test, d.f. $=8$; low resources: $P<0.02$ ) and HSM was greater for desert species (high resources: $P<0.006)$.

However, several of the traits that did not show significant source effects in the ANOVA did so in the PICs in at least one of the resource treatments (Table 4). These include time to emergence, leaf number, and LAR. The surprising lack of source effects on RGR was confirmed by the PICs. Including phylogenetic information in the analyses seems to make it easier, although not inevitable, to detect differences between desert and coastal species.

Taxonomic identity was more important than source habitat in explaining trait means and how traits changed in response to treatments, in terms of significance of differences (compare their main effects and interactions with resources in Table 3 ) and in terms of magnitude of change (Fig. 1). Legumes tended to have more leaf area and shoot mass than grasses and forbs at low resources, while forbs were largest at high resources (Fig. 1d,f). This change in rank size between treatments was because legumes responded much less in shoot RGR, and thus size, to an increase in resources than did grasses or, especially, forbs. Shoot and root RGR of grasses and forbs increased two- to threefold under high resources, while shoot RGR in legumes increased only $75 \%$, and root RGR did not change at all (Fig. 1g,h). Morphologically, the responsiveness of the taxonomic groups differed quantitatively in ways consistent with their typical phenotypes: grasses became shorter for a given shoot mass, allocated less to roots, and had larger ULR, while forbs had larger LAR and tended to show a greater increase in root size (RLM). Legumes were less responsive to increased resources compared to one or both of the other two taxonomic groups for all the morphological traits except RWR.

In contrast to the strong differences among taxonomic groups in response to increased resources, taxonomic differences were mostly consistent between 


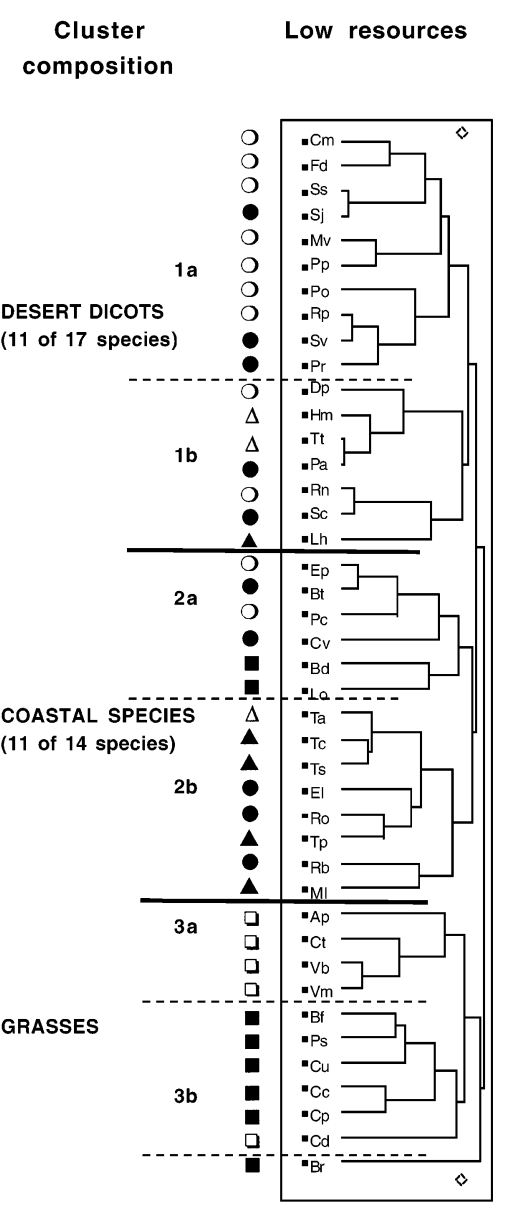

Cluster
composition

High resources
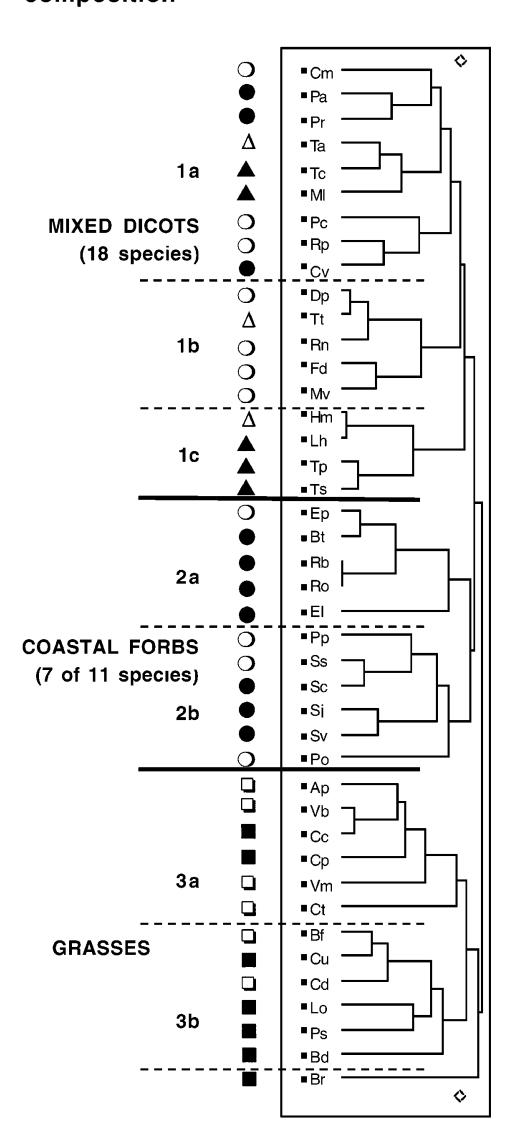

Fig. 2. Dendrograms from hierarchical cluster analysis showing relationships between 42 taxa grown at low- and high-resource treatments and based on the 14 traits listed in Table 2. Dark horizontal lines separate taxa into major clusters (numbered); dashed horizontal lines subdivide the major clusters (lower case letters). Species abbreviations are taken from Table 1. Grasses are indicated by squares, forbs by circles, and legumes by triangles; desert species are indicated by open symbols, coastal species by shaded symbols. Bromus rigidus was associated with other grasses, but was a considered an outlier. the two habitats (contrast taxonomic groups $\times$ resource interactions with taxonomic group $\times$ source interactions in Table 3). However, there were two exceptions to the latter. First, shoot RGR of desert legumes exceeded that of coast legumes, while grasses and forbs had very similar shoot RGRs between habitats (Fig. 1g). The opposite pattern was seen for HSM: legumes did not differ between the sources while both grasses and forbs from the coast were larger relative to their height than their desert counterparts (Fig. 11).

\section{SPECIES CLUSTERS}

The dendrograms from the two resource treatments were organized similarly with three general species clusters, but the clusters were not identical between treatments with respect to within-cluster species composition (Fig. 2). In the low-resource treatment we identified a grass cluster, a cluster of mostly coastal dicots (forbs and legumes), and a cluster of mostly desert dicots. In the high-resource treatment we identified a grass cluster, a cluster of mostly coastal forbs, and a cluster containing a mixture of forbs and all of the legumes.

Protected multiple comparison tests (Tukey's HSD) showed that the means of at least two of the three clusters within each dendrogram differed significantly from each other for nearly every trait (Table 5). The grass cluster in both resource treatments was characterized by longer time to emergence, taller plants (both absolute and relative to weight), larger RWR and ULR, and smaller leaf area and LAR. The separation of dicots into the two remaining clusters was based on significant differences for many traits, but the specific traits differed between treatments (Table 5). At low

Table 5 Trait means and multiple comparisons (Tukey's HSD) of species clusters in low- and high-resource treatments. Cluster membership taken from results of cluster analysis shown in Fig. 2. Different letters within a treatment represent significant differences $(P<0.05)$ between clusters within each trait. PCA rotated values (Table 6; Fig. 3) were analysed similarly

\begin{tabular}{|c|c|c|c|c|c|c|}
\hline \multirow[b]{2}{*}{ Trait } & \multicolumn{3}{|c|}{ Low resources } & \multicolumn{3}{|c|}{ High resources } \\
\hline & Mostly desert & Mostly coastal & Grass & Mixed dicots & Coastal forbs & Grass \\
\hline Seed mass & $0 \cdot 052 b$ & $0 \cdot 226 \mathrm{a}$ & $0 \cdot 081 \mathrm{~b}$ & $0 \cdot 135 \mathrm{a}$ & $0 \cdot 101 \mathrm{a}$ & $0 \cdot 109 \mathrm{a}$ \\
\hline Time to emergence & $4 \cdot 89 \mathrm{~b}$ & $6 \cdot 02 \mathrm{ab}$ & $7 \cdot 02 \mathrm{a}$ & $4 \cdot 91 \mathrm{~b}$ & $5 \cdot 21 \mathrm{~b}$ & $6 \cdot 78 \mathrm{a}$ \\
\hline Leaf number & $4 \cdot 27 \mathrm{a}$ & $4 \cdot 31 \mathrm{a}$ & $1.75 b$ & $10 \cdot 3 a$ & $7 \cdot 60 \mathrm{~b}$ & $3 \cdot 62 \mathrm{c}$ \\
\hline Leaf area & $0 \cdot 105 \mathrm{ab}$ & $0.635 \mathrm{a}$ & $0 \cdot 034 \mathrm{~b}$ & $2 \cdot 12 b$ & $7 \cdot 43 a$ & $1 \cdot 68 \mathrm{~b}$ \\
\hline Plant height & $17 \cdot 0 \mathrm{c}$ & $37 \cdot 1 b$ & $58 \cdot 8 \mathrm{a}$ & $41 \cdot 8 b$ & $47 \cdot 6 b$ & $134 \mathrm{a}$ \\
\hline Root mass & $0 \cdot 228 b$ & $1 \cdot 42 \mathrm{a}$ & $0 \cdot 650 \mathrm{~b}$ & $0.92 \mathrm{a}$ & $1 \cdot 86 \mathrm{a}$ & $1.78 \mathrm{a}$ \\
\hline Shoot mass & $0 \cdot 621 b$ & $3 \cdot 63 \mathrm{a}$ & $0 \cdot 655 b$ & $7 \cdot 20 \mathrm{~b}$ & $18 \cdot 0 \mathrm{a}$ & $6 \cdot 77 \mathrm{~b}$ \\
\hline $\mathrm{RGRr}$ & $0 \cdot 101 \mathrm{a}$ & $0 \cdot 090 \mathrm{a}$ & $0 \cdot 139 \mathrm{a}$ & $0 \cdot 145 b$ & $0 \cdot 232 \mathrm{a}$ & $0 \cdot 228 \mathrm{a}$ \\
\hline RGRs & $0 \cdot 056 \mathrm{a}$ & $0 \cdot 070 \mathrm{a}$ & $0 \cdot 068 \mathrm{a}$ & $0 \cdot 144 b$ & $0 \cdot 207 \mathrm{a}$ & $0 \cdot 176 \mathrm{ab}$ \\
\hline LAR & $160 \mathrm{a}$ & $131 \mathrm{a}$ & $23 \cdot 8 b$ & $255 b$ & $405 \mathrm{a}$ & $179 \mathrm{c}$ \\
\hline RLM & $165 \mathrm{a}$ & $96 \cdot 5 b$ & $135 \mathrm{a}$ & $107 \mathrm{a}$ & $62 \cdot 4 b$ & $125 \mathrm{a}$ \\
\hline HSM & $34 \cdot 8 b$ & $14 \cdot 1 \mathrm{c}$ & $113 \cdot 5 \mathrm{a}$ & $11 \cdot 7 \mathrm{~b}$ & $7 \cdot 13 b$ & $39 \cdot 8 \mathrm{a}$ \\
\hline RWR & $0 \cdot 228 b$ & $0 \cdot 278 b$ & $0 \cdot 464 \mathrm{a}$ & $0 \cdot 114 b$ & $0.093 b$ & $0 \cdot 190 \mathrm{a}$ \\
\hline ULR & $0 \cdot 602 b$ & $0 \cdot 748 b$ & $6 \cdot 62 \mathrm{a}$ & $2 \cdot 17 \mathrm{~b}$ & $4 \cdot 52 \mathrm{ab}$ & $8 \cdot 43 a$ \\
\hline PCA Axis 1 & $-0 \cdot 599 b$ & $0 \cdot 682 \mathrm{a}$ & $-0 \cdot 392 b$ & $-0 \cdot 310 \mathrm{~b}$ & $0 \cdot 496 \mathrm{a}$ & $-0 \cdot 360 \mathrm{~b}$ \\
\hline PCA Axis 2 & $0 \cdot 545 \mathrm{a}$ & $0 \cdot 945 \mathrm{a}$ & $-1 \cdot 491 b$ & $0 \cdot 442 b$ & $0 \cdot 852 \mathrm{a}$ & $-1 \cdot 237 \mathrm{c}$ \\
\hline PCA Axis 3 & $-0 \cdot 276 a$ & $0 \cdot 211 \mathrm{a}$ & $0 \cdot 355 \mathrm{a}$ & $-0 \cdot 725 b$ & $0 \cdot 792 \mathrm{a}$ & $0 \cdot 436 \mathrm{a}$ \\
\hline
\end{tabular}


Table 6. Loadings of 14 traits in the first three principal components (values $>0.30$ in bold) in separate principal components analyses (PCA) for plants growing in low- and high-resource treatments. Variance explained by each axis (eigenvalue) in parentheses

\begin{tabular}{|c|c|c|c|c|c|c|}
\hline \multirow[b]{3}{*}{ Trait } & \multicolumn{6}{|c|}{ Principal component } \\
\hline & \multicolumn{3}{|c|}{ Low resources } & \multicolumn{3}{|c|}{ High resources } \\
\hline & Axis 1 & Axis 2 & Axis 3 & Axis 1 & Axis 2 & Axis 3 \\
\hline (Eigenvalue) & $(33 \cdot 28)$ & $(30 \cdot 88)$ & $(9 \cdot 42)$ & $(31 \cdot 77)$ & $(26 \cdot 19)$ & $(17 \cdot 61)$ \\
\hline Seed mass & $0 \cdot 360$ & $0 \cdot 195$ & $-0 \cdot 244$ & $0 \cdot 351$ & $-0 \cdot 212$ & $-0 \cdot 258$ \\
\hline Time to emergence & $0 \cdot 141$ & $-0 \cdot 233$ & $-0 \cdot 122$ & $-0 \cdot 117$ & $-0 \cdot 327$ & $0 \cdot 209$ \\
\hline Leaf number & $-0 \cdot 167$ & $0 \cdot 334$ & $0 \cdot 212$ & $0 \cdot 060$ & $0 \cdot 359$ & $-0 \cdot 089$ \\
\hline Leaf area & $0 \cdot 275$ & $0 \cdot 356$ & 0.027 & $0 \cdot 421$ & $-0 \cdot 015$ & $0 \cdot 159$ \\
\hline Plant height & $0 \cdot 413$ & $-0 \cdot 119$ & $-0 \cdot 034$ & $0 \cdot 159$ & -0.439 & $-0 \cdot 040$ \\
\hline Root mass & $0 \cdot 387$ & $0 \cdot 176$ & $-0 \cdot 211$ & $0 \cdot 382$ & $-0 \cdot 257$ & $-0 \cdot 070$ \\
\hline Shoot mass & $0 \cdot 298$ & $0 \cdot 328$ & $0 \cdot 086$ & $0 \cdot 444$ & $-0 \cdot 089$ & $0 \cdot 077$ \\
\hline RGRr & $0 \cdot 125$ & $-0 \cdot 176$ & $0 \cdot 464$ & -0.089 & $-0 \cdot 153$ & $0 \cdot 503$ \\
\hline RGRs & 0.092 & $0 \cdot 020$ & $0 \cdot 725$ & $0 \cdot 063$ & $-0 \cdot 055$ & $0 \cdot 582$ \\
\hline LAR & $-0 \cdot 251$ & $0 \cdot 320$ & -0.057 & $0 \cdot 193$ & $0 \cdot 272$ & $0 \cdot 355$ \\
\hline RLM & -0.331 & $-0 \cdot 175$ & $-0 \cdot 165$ & $-0 \cdot 358$ & -0.060 & $-0 \cdot 111$ \\
\hline HSM & $0 \cdot 052$ & $-0 \cdot 431$ & $-0 \cdot 126$ & $-0 \cdot 302$ & -0.338 & $-0 \cdot 050$ \\
\hline RWR & $0 \cdot 340$ & $-0 \cdot 244$ & -0.035 & $0 \cdot 046$ & -0.387 & $-0 \cdot 215$ \\
\hline ULR & $0 \cdot 147$ & -0.327 & $0 \cdot 194$ & $-0 \cdot 206$ & $-0 \cdot 292$ & 0.257 \\
\hline
\end{tabular}

resources, the mostly desert dicot cluster was distinguished from the mostly coastal dicot cluster by having smaller seeds and plants (leaf area, height, root and shoot mass); thinner roots (increased RLM); and smaller mass relative to height (increased HSM). At high resources, the mixed dicot cluster was distinguished from the mostly coastal forb cluster by more leaves per plant, but smaller leaf area, shoot mass, root RGR, shoot RGR and LAR, and thinner roots (Table 5).

\section{PRINCIPAL COMPONENTS ANALYSIS}

In both treatments, the first three principal components accounted for about $75 \%$ of the variation in the data. However, the traits with the highest absolute correlations with each principal component differed between treatments (Table 6). In the low-resource treatment the first axis was heavily weighted toward overall plant size and root characteristics. Increasing values on PCA axis 1 indicated greater absolute root mass and allocation to roots, thicker roots, and taller plants with larger seeds (Fig. 3a). The second axis was related to leaf and shoot characteristics; increasing values of PCA axis 2 indicated fewer leaves and smaller leaf area, LAR and shoot mass, but taller plants relative to mass, and larger ULR. The second axis clearly separated grasses from dicots (Fig. 3). In the high-resource treatment the first two axes were not so clearly divided into root and shoot characteristics. Increasing values of axis 1 indicated larger plants, with greater leaf area and thicker roots, while decreasing values of axis 2 indicated taller plants (both absolutely and relative to shoot weight) with fewer leaves and more allocation to roots. Again, the second axis distinguished grasses from dicots. In both treatments root and shoot RGR were the main components of
Ecological Society, Functional Ecology, 15, 85-95

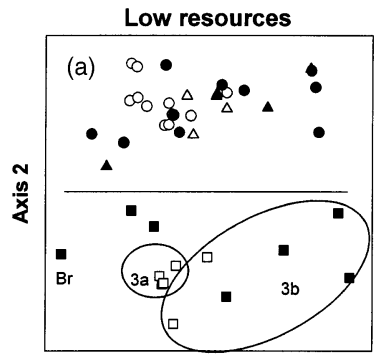

Axis 1

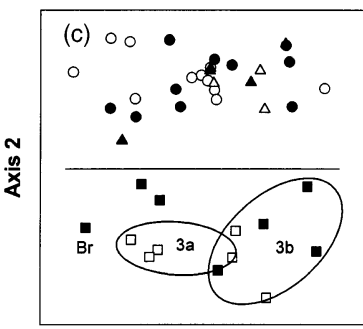

Axis 3

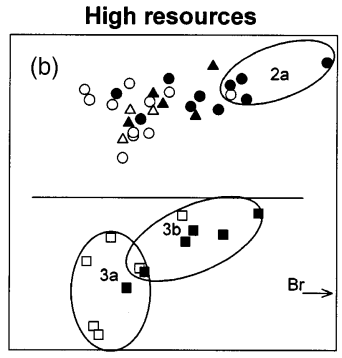

Axis 1

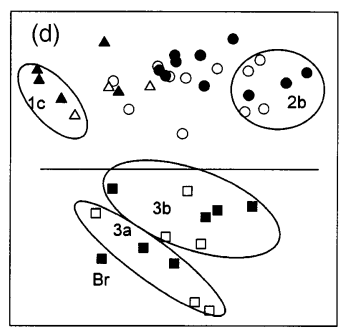

Axis 3
Fig. 3. Plots of PCA scores from 14 traits for 42 taxa grown in low- and high-resource treatments. Traits with high correlations to the three principal components are shown in Table 6 . In all cases, values increase to the right on the $x$-axis and to the top on the $y$-axis. Horizontal straight lines separate grasses from dicots. Large ellipses indicate the subdivisions identified by the hierarchical clustering technique shown in Fig. 2, but only where the divisions could be clearly indicated. Separation of the three main clusters described in Fig. 2 was significant $(P<0.05)$ by one-way ANOvA on the PCA scores for all axes except axis 3 in the low-resource treatment (see bottom of Table 5). Species symbols follow Table 1.

the third axis; increasing values of axis 3 indicated faster root and shoot RGR.

One-way ANOVA comparing the species PCA scores among the clusters defined in Fig. 3 showed significant separation of cluster means for axes 1 and 2 for the low-resource treatment, and for all three axes for the high-resource treatment (Table 5). These results suggest that distinctions between species grown under low-resource conditions are influenced more by belowground processes and above-ground morphology than by growth rate. However, when the functional groups defined by the cluster analysis are indicated on the PCA plots in Fig. 3, distinctions between grasses and dicots are obvious, but not between the two dicot groups.

\section{Discussion}

The goal of this study was to investigate the response patterns of a large number of annual species with respect to the quality of their source habitat, their taxonomic affiliation, and the conditions under which they were grown. We found that plastic and, to a lesser extent, fixed responses of plants to changes in resource availability strongly supported many general predictions from ecological theory (Fig. 1). However, definitions of PFGs were not independent of growing 
93

Effects on plant

traits and

functional groups conditions, in terms of both the species membership of the groups and the relationships among the traits defining the groups. This result was somewhat surprising given our use of a single growth form. One serious consequence of surveying plants representing a range of growth forms or age classes is that clustering techniques consistently identify groups based mainly on coarse morphological and structural attributes (Lavorel et al. 1997), and subtle within-group variation is either not detected or is ignored. Such results suggest that complex multivariate procedures do not seem to be an improvement over simple visual assessment for defining PFGs. In this study, the strong within-group plastic variation indicated the individuality of species' responses and the importance of multivariate approaches for investigating similarities among species.

\section{ARE GROWTH AND MORPHOLOGY}

\section{AFFECTED BY RESOURCE AVAILABILITY?}

The effect of resource availability on size and shape characteristics of the 42 taxa in this study closely matched predictions and previous studies (Berendse \& Elberse 1990; Chapin 1980; Grime 1979; Poorter \& Remkes 1990). Although it is hardly surprising that an increase in nutrients increased size and growth rate, it is less trivial that morphology also changed. As predicted, increased resource availability during growth led to a decrease in relative allocation to roots, thinner leaves, and increased ULR. Contrary to prediction, at higher resources plants from the two sources were not different in the ratio of height to shoot weight, probably because these plants were grown individually. Under competitive, resource-rich conditions, however, vertical as opposed to horizontal growth will be advantageous to maximize light interception by each canopy.

Plants from the more productive coastal habitat were larger and more robust than desert species in both treatments (Table 5; Fig. 1). However, shoot and root RGR were notable exceptions and did not differ between habitats even at high resource availability. This is not consistent with most data in the literature, where maximum potential $\mathrm{RGR}\left(\mathrm{RGR}_{\max }\right)$ is often correlated with habitat productivity (Chapin 1980; Grime 1977; Grime \& Hunt 1975; Lambers \& Poorter 1992; Tilman 1990; Wright \& Westoby 1999).

The lack of habitat effects on shoot RGR, LAR and RWR may partly reflect our exclusive use of annuals, a life form characterized by high $\mathrm{RGR}_{\max }$ (Grime 1977). The range of shoot RGR presented here is similar to those reported previously (Grime \& Hunt 1975; Poorter \& Remkes 1990; Shipley 1989; Shipley \& Peters 1990) and in studies where a relationship between growth rate and habitat productivity was reported (Elberse \& Berendse 1993; Fichter \& Schulze 1992; Poorter \& Remkes 1990; Tilman \& Cowen 1989). However, separating these species by habitat on the basis of traits related to growth rate may be very difficult, because annual species respond strongly to resource availability. The two habitats are relatively infertile, and the functional characteristics of the species studied may be associated more strongly with taxonomic affiliation than ecotypic variation.

\section{CAN PFGS BE DEFINED ROBUSTLY AND DO THEY REFLECT A PRIORI GROUPINGS BASED ON TAXONOMIC AFFILIATION AND/OR HABITAT?}

Cluster analysis identified groups of taxa in both treatments, but whether the distinctions between species were related to habitat or to taxonomic affiliation depended on the treatment. Both PCA and cluster analysis recognized the morphological, and therefore taxonomic, distinctions between monocots and dicots in the high-resource treatment, and generally so in the low-resource treatment. Overall the results were consistent with the critique of Lavorel et al. (1997), in that a serious consequence of surveying plants representing a range of growth forms or age classes is that clustering techniques consistently identify PFGs based mainly on coarse morphological or structural attributes. On the other hand, the cluster analysis and, to a lesser extent, the PCA also found more subtle groupings of similar species that would not be easily distinguished by less-sophisticated analyses, and that were only partly reflective of the a priori groups based on source habitat or taxonomy. The cluster analysis, but not the PCA, separated the dicots largely by source habitat in the low-resource treatment, but distinguished between coastal forbs and the rest of the dicots (including legumes) in the high-resource treatment based largely on growth rates. There were also clear subdivisions within clusters that were not related to more subtle taxonomic separation between families, or to obvious morphological differences such as rosette formation versus upright stature. Among the dicots, legumes were less responsive to resource availability compared to forbs. Within treatments, however, the legumes did not separate clearly from other dicots, despite the significant differences between the taxonomic groups in the univariate analyses. Similarly, we found no strong differences in correlated suites of traits between the two habitats despite significant univariate differences for several traits. Multivariate analyses were therefore essential for revealing patterns in trait associations that were not detected in univariate analyses.

ARE PFGS FOUND IN DIFFERENT RESOURCE TREATMENTS CONSISTENTLY DEFINED BY THE SAME SPECIES OR BY THE SAME TRAITS?

Although broadly similar, the PFGs we found in the two resource treatments were neither identical in composition (Fig. 2) nor characterized by the same 15, 85-95 
suites of traits (Table 6). Additionally, the traits that distinguished the PFGs differed between treatments and the patterns of differences among the groups were different (Table 5). The difference in species composition between groups can be seen most clearly with seed mass, a trait that is unaffected by the resource treatment, but which had different mean cluster values between treatments. Although inferential statistical procedures could not be used to verify the PFGs, non-response traits such as seed mass are useful for indicating significant realignment of species among the groups.

The taxonomic distinction between grasses and dicots was relatively unaffected by the treatments, although about $30 \%$ of the dicots moved among groups defined by the cluster analysis. The direction and magnitude of response within the dicots must have been due to differences in response plasticity among the species within the groups defined in the two growing environments. Both grasses and dicots responded to changes in resource availability, but trait correlations among dicots were especially labile. Specifically, the grasses, rather than the dicots, had either the highest or lowest means for all traits in both treatments. In contrast, the relationship between nine of the 14 trait means of the two dicot groups was inconsistent across the resource treatments. Therefore, changes in phenotypic integration with resource availability may be a significant difference between the monocots and dicots we tested.

Most studies that attempt to identify PFGs have analysed 'static' measures of morphology, one-time measures of mature plants in one environment rather than of their responses to environmental change. Our data indicate that this approach may cause problems, because the magnitude of the plastic responses of each species to the resource treatments affected the outcome of our analyses. This implies that functional group membership, empirically defined, may be conditional: while the responses of individual species may satisfy theoretical predictions, species membership and trait-based definitions of PFGs behave unpredictably. Our results provide empirical support for the importance of using response-based approaches to PFG analysis, as exemplified by the work of Grime et al. (1997) and Hunt \& Cornelissen (1997).

\section{IMPLICATIONS FOR USING PFG ANALYSIS} FOR PREDICTING VEGETATION SHIFTS DUE TO ENVIRONMENTAL CHANGE

Researchers interested in broad management applications might be less interested in the dynamics within functional groups. However, the idiosyncratic responses of individual species suggest that some attention should be given to the effects of environmental change on the contribution of each species to the community. The adaptive significance of plastic response is poorly understood and has largely unknown consequences for populations and communities. This does not mean that PFG analysis is not useful for habitat conservation or for investigating broad floristic shifts related to factors such as grazing and climate change. It does, however, suggest that predicting the effects of these factors on the behaviour of individual species based on their membership in PFGs may be problematic. The sensitivity of the analysis to the behaviour of individual species will be lost as PFGs represent more general structural and physical patterns of the vegetation. Further, if the responses of individual species to changing conditions are important to the subsequent structure of the community, the effects of environmental change on community-level processes may be unpredictable through PFG analysis.

\section{Acknowledgements}

This work was made possible by the US-Israel BiNational Science Foundation (BSF 91-00179 to D. E. Goldberg and L. Olsvig-Whittaker), the National Science Foundation (NSF grant \#96-2723 to D. E. Goldberg, R. Turkington and J. Gurevitch), the Natural Sciences and Engineering Research Council, Canada (to R. Turkington), and facilities at the University of British Columbia and the Mitrani Center for Desert Ecology of the Blaustein Institute for Desert Research, Ben Gurion University, Sede Boker Campus, Israel. Our thanks to Bill Shipley for a constructive review. This is publication no. 303 of the Mitrani Department of Desert Ecology.

\section{References}

Berendse, F. \& Elberse, W.Th (1990) Competition and nutrient availability in heathland and grassland ecosystems. Perspectives on Plant Competition (eds J. Grace \& D. Tilman), pp. 93-116. Academic Press, San Diego.

Chapin, F.S. III (1980) The mineral nutrition of wild plants. Annual Review of Ecology and Systematics 11, 233-260.

Chapin, F.S. III (1991) Integrated responses of plants to stress. Bioscience 41, 29-36.

Diaz, S. \& Cabido, M. (1997) Plant functional types and ecosystem function in relation to global change. Journal of Vegetation Science 8, 63-474.

Elberse, W.Th. \& Berendse, F. (1993) A comparative study of the growth and morphology of eight grass species from habitats with different nutrient availabilities. Functional Ecology 7, 223-229.

Feinbrun-Dothan, N. \& Danin, A. (1991). Analytical Flora of the Land of Israel. Cana, Jerusalem.

Fichter, K. \& Schulze, E.-D. (1992) The effect of nitrogen on growth and biomass partitioning of annual plants originating from habitats of different nitrogen availability. Oecologia 92, 236-241.

Gitay, H. \& Noble, I.R. (1997) What are functional types and how should we seek them? Plant Functional Types, Their Relevance to Ecosystem Properties and Global Change (eds T. M. Smith, H. H. Shugart \& F. I. Woodward), pp. 3-19. Cambridge University Press, Cambridge, UK.

Grime, J.P. (1977) Evidence for the existence of three primary strategies in plants and its relevance to ecological and evolutionary theory. American Naturalist 111, 1169-1194.
Functional Ecology $\mathbf{1 5}, 85-95$
C 2001 British Ecological Society, 
Effects on plant

traits and

functional groups
Grime, J.P. (1979) Plant Strategies and Vegetation Processes. Wiley, Chichester, UK.

Grime, J.P. \& Hunt, R. (1975) Relative growth rate: its range and adaptive significance in a local flora. Journal of Ecology 63, 393-422.

Grime, J.P., Thompson, K. \& Hunt, R. (1997) Integrated screening validates primary axes of specialisation in plants. Oikos 79, 259-281.

Hendry, G.A.F. \& Grime, J.P. (1993) Methods in Comparative Plant Ecology - A Laboratory Manual. Chapman \& Hall, London.

Hunt, R. \& Cornelissen, J.H.C. (1997) Components of relative growth rate and their interrelations in 59 temperate plant species. New Phytologist 135, 395-417.

Lambers, H. \& Poorter, H. (1992) Inherent variation in growth rate between higher plants: a search for physiological causes and ecological consequences. Advances in Ecological Research 23, 187-261.

Lavorel, S., McIntyre, S., Landsberg, J. \& Forbes, T.D.A. (1997) Plant functional classifications: from general groups to specific groups based on response to disturbance. Trends in Ecology and Evolution 12, 474-478.

McIntyre, S., Lavorel, S. \& Tremont, R.M. (1995) Plant life-history attributes: their relationship to disturbance response in herbaceous vegetation. Journal of Ecology 83, $31-44$.

Poorter, H. \& Remkes, C. (1990) Leaf area ratio and net assimilation rate of 24 wild species differing in relative growth rate. Oecologia $\mathbf{8 3}, 553-559$.

Schlichting, C.D. (1986) The evolution of phenotypic plasticity in plants. Annual Review of Ecology and Systematics 17, 667-693.

Shipley, B. (1989) The use of above-ground maximum relative growth rate as an accurate predictor of whole-plant maximum relative growth rate. Functional Ecology 3, 771-775.

Shipley, B. \& Peters, R.H. (1990) A test of the Tilman model of plant strategies: relative growth rate and biomass partitioning. American Naturalist 136, 139-153.

Silvertown, J. \& Dodd, M. (1996) Comparing plants and connecting traits. Philosophical Transactions of the Royal Society, London B 351, 1233-1239.

Smith, T.M., Shugart, H.H. \& Woodward, F.I., eds (1997) Plant Functional Types, Their Relevance to Ecosystem Properties and Global Change. Cambridge University Press, Cambridge, UK.

Stebbins, G.L. (1974) Flowering Plants: Evolution above the Species Level. Belnap Press, Harvard, MA, USA.

Tilman, D. (1988) Plant Strategies and the Dynamics and Structure of Plant Communities. Princeton University Press, Princeton, NJ, USA.

Tilman, D. (1990) Mechanisms of plant competition for nutrients: the elements of a predictive theory of competition. Perspectives on Plant Competition (eds J. Grace \& D. Tilman), pp. 117-141. Academic Press, San Diego.

Tilman, D. \& Cowen, M.L. (1989) Growth of old field herbs on a nitrogen gradient. Functional Ecology 3, 425-438.

Westoby, M. (1998) A leaf-height-seed (LHS) plant ecology strategy scheme. Plant and Soil 199, 213-227.

Wright, I.J. \& Westoby, M. (1999) Differences in seedling growth behaviour among species: trait correlations across species, and trait shifts along nutrient compared to rainfall gradients. Journal of Ecology 87, 85-97.

Zohary, M. (1982) Vegetation of Israel and Adjacent Areas. Dr. Ludwig Reichert, Wiesbaden, Germany.

Received 3 April 2000; revised 1 August 2000; accepted 4 August 2000
(C) 2001 British

Ecological Society,

Functional Ecology, 15, 85-95 